\title{
The impact of class attendance on student performance
}

\author{
Tarig Fadelelmoula
}

Almaarefa Colleges, Riyadh, Saudi Arabia.

Accepted 28 May, 2018

\begin{abstract}
Students' class attendance and engagement plays an important role in contemporary higher education. The present study aimed to investigate the compliance of Respiratory Care students to attendance regulations and the relationship between mandatory class attendance and final exam performance in four Respiratory Care courses. Attendance was measured by the overall lecture attendance percent, throughout the course. Students' performance was assessed by the final exam mark obtained. No statistically significant differences in student attendance between the different courses were found; although attendance was lower in cardiopulmonary anatomy and physiology course compared with the other 3 courses. Statistically significant differences in performance were present between the four courses. Positive correlation was found between attendance and final exam performance in all courses together, but the relationship between the variables was not statistically significant. Correlation between attendance and final exam results for each separate course was also examined and found to be positive, but also lacked statistical significance. Students' compliance with the student regulations and the overall attendance is excellent. Class attendance got a positive impact on students' academic performance. This suggests that lecture attendance is critical for learning, but a larger study is required to adjust for other factors like, English language proficiency student CGPA (cumulative average grade point) and gender and to minimize the effect of the small sample size used in this pilot study.
\end{abstract}

Keywords: Attendance, performance, final exam, respiratory care.

E-mail: Eltarig70@hotmail.com. Tel: +966542521796.

\section{INTRODUCTION}

The economic concerns of education have led to many studies aiming at identifying the determinants of student performance (Stanca, 2006).

In his famous paper "Do students go to class? Should they?" Romer (1993) analyzed the relationship between lecture attendance and exam performance. Using attendance records in six sessions of 195 students in Intermediate Macroeconomics Course, he found that attendance had a positive and significant impact on academic performance. On the basis of these findings, he recommended experimenting with mandatory attendance policies to enhance student performance.

Students' class attendance and engagement plays an important role in contemporary higher education. Several previous studies have shown that class attendance is an important determinant of academic outcomes: students who attend more classes earn higher final grades (Kirby and McElroy, 2003). However, differing results exist as well. In a recent study, no statistically significant relationship between class attendance and student performance was identified after adjusting for control variables that included gender and age (Eisen et al., 2015). In a study conducted in Saudi Arabia by Alghamdi and his team, the overall percentage of absenteeism was comparable to that of the studies carried out regionally and internationally. The study showed the performance GPA mean is influenced by low attendance rates (Alghamdi et al., 2016).

In another study conducted by Bamuhair and her colleagues in College of Medicine, King Saud Bin Abdulaziz University for Health Sciences in The Kingdom of Saudi Arabia, class attendance showed a positive effect on students' academic performance with stronger effect for lecture attendance compared to attendance in 
other teaching modalities (Bamuhair et al., 2016).

Although no study has provided data about the adherence of undergraduate student to attendance, Alghamdi and his team have looked into the causes for absenteeism and he pointed out unfavorable teaching strategies, preparation for examinations, early-morning classes and social causes like marriage and part time job as the main cause at their setting and they recommend working on the causes of absenteeism to further increase the rate of attendance of all academic activities (Alghamdi et al., 2016).

Many institutions adopt non-mandatory attendance policy for their students and researches have clearly shown the positive relation between non-mandatory attendance and student performance.

The objective of this study is to investigate the compliance of respiratory care students to attendance regulations and the relationship between mandatory class attendance and final exam performance in four courses.

\section{MATERIALS AND METHODS}

\section{Purpose}

A retrospective study for the impact of student class attendance on their final exam results in 4 courses within a full academic semester (second semester academic year 2016-2017), general information about these courses is provided in Table 1. In these courses attendance is mandatory and students are requested to attend $75 \%$ or more of the course classes to be allowed to sit for the final exam.

\section{Research questions}

The study was designed to answer two questions:

1. Do students comply with class attendance rules?

2. Whether student class attendance impacts their final exam results or not?

\section{Target group and data collection}

All respiratory care students who completed these courses were included in the study. Student attendance for lectures was recorded using a paper-based system before transferring it to the college portal by the course instructor.

The students' attendance was measured by the overall attendance percent, which is a product of attending various lectures throughout the course and the average students' performance in the four courses together was assessed by the final exam mark obtained.

The study was conducted within the male section, Department of Respiratory Care, College of Applied Sciences, Almaarefa Colleges for Science \& Technology, Kingdom of Saudi Arabia.

\section{Data analysis}

All students' attendance percentages and their final exam assessment results will be described using mean (M) and standard deviation (SD). Correlation will be used to predict the effect of overall attendance on the students' final marks. All statistical tests used are two-tailed. A p-value of 0.05 or less will be taken as statistically significant. The data will be analyzed using the Statistical Package for the Social Sciences (SPSS), Version 21.0 (IBM Corporation, Armonk, NY, USA).

Table 1. Identification and general information about study courses.

\begin{tabular}{lcc}
\hline Course name (code) & Credit hours & No. of weeks \\
\hline Cardiopulmonary Anatomy and Physiology (RSTH 225) & 3 & 15 \\
Cardiology and Electrocardiography (RSTH 330) & 4 & 15 \\
Respiratory Care Science II (RSTH 342) & 4 & 15 \\
Exercise Physiology and Pulmonary Rehab (RSTH 424) & 3 & 15 \\
\hline
\end{tabular}

\section{RESULTS}

\section{Class attendance}

Four courses were included in the study (Table 1), comprising 75 students and all of them were males $(100 \%)$. The mean students' attendance 92\%, $(S D=4.8)$.

\section{Student performance}

Table 2 shows the students' attendance and final exam results for each of the four separate courses as means and standard deviations. No statistically significant differences were found in student attendance between the different courses, although attendance was lower in
Cardiopulmonary Anatomy and Physiology course compared with the other 3 courses. Statistically significant differences in student performance in the final course exams were present between the four courses $(p$ $<0.001$ ). A positive correlation was found between attendance and final exam performance in all courses together $(N=75)$, but the correlation between the variables was not statistically significant $(r=0.2177, p>$ 0.05). Correlation between students' attendance and their final exam results for each separate course was also examined and found to be positive, but also lacked statistical significance.

\section{DISCUSSION}

In our setting, the college strongly applies a mandatory 
Table 2. Students' attendance and final exam results.

\begin{tabular}{llccccc}
\hline \multirow{2}{*}{ Course name } & \multirow{2}{*}{ Students (N) } & \multicolumn{2}{c}{ Attendance (\%) } & & \multicolumn{2}{c}{ Final exam result (out of 30) } \\
& & Mean & SD & & Mean & SD \\
\hline Respiratory Care Science II & 20 & 92.6 & 6.2 & & 24 & 2.9 \\
Cardiology and ECG & 16 & 92.3 & 4.8 & & 19.2 & 4.8 \\
Exercise \& Rehabilitation & 21 & 92.2 & 2.8 & & 26.5 & 2.3 \\
Cardiopulmonary A \& P & 18 & 91 & 5.5 & & 17.7 & 3.7 \\
\hline
\end{tabular}

attendance policy and every student has to attend $75 \%$ or more of the total classes in order to be allowed to sit for the final exam. During the course time, student attendance is closely recorded and monitored by the course instructor and students are continuously informed about the attendance together with their exam permission situation. If student has $10 \%$ absenteeism, he will have his first warning, when absenteeism reaches $20 \%$ student will have a second warning and will be counseled by his academic advisor before reaching $25 \%$ absenteeism which will signify denial of student sitting for exams, namely for first midterm, second midterm and final exam. In our college final exam is composed of multiple choice questions of the single correct answer type and OSCE stations if the course contains a practical component. The exam results are usually graded in a system of $A_{+}, A, B+$, $\mathrm{B}, \mathrm{C}+, \mathrm{C}, \mathrm{D+}, \mathrm{D}$ and $\mathrm{E}$ which is a clear failure. The overall student attendance in our setting is acceptable and this result reflects the importance of strict regulations to force student for attending the theoretical classes. The study demonstrated a positive correlation between lecture attendance and final exam performance. Although the results were not statistically positive, they agree with local and international studies (Kirby and McElroy, 2003). The study is limited by the small sample size and does not include student academic level and other factors that might influence student performance in exams such as their gender and cumulative grade point average (Alghamdi et al., 2016). Another important limiting factor in this study is that students are allowed to withdraw from the course and final exam if their performance in the midterm exams is poor and this will bias the sample that we are taking to reflect the relationship between class attendance and performance among students.

\section{CONCLUSION AND RECOMMENDATIONS}

Lecture attendance has a positive effect on students' academic performance and hence a mandatory attendance policy is important. This suggests that lecture attendance is critical for learning, but a larger study is required to adjust for other factors like student CGPA and to minimize the effect of the small sample size used in this pilot study.

\section{ACKNOWLEDGEMENT}

The author wishes to thank Almaarefa Colleges for Science and Technology, Riyadh, for providing the required data for the study.

\section{Disclosure}

The author reports no conflicts of interest in this work.

\section{REFERENCES}

Alghamdi A, Yamani A, Khalil A, Albarkati B, Alrehili O, Salih M, 2016. Prevalence, causes and impacts of absenteeism among medical students at UQU. Education, 6(1): 9-12.

Bamuhair SS, AI Farhan AI, Althubaiti A, Ur Rahman S, AI-Kadri HM, 2016. Class attendance and cardiology examination performance: a study in problem-based medical curriculum. Int J Gen Med, 9: 1-5.

Eisen D, Schupp C, Isserof R, Ibrahimi O, Ledo L, Armstrong A, 2015. Does class attendance matter? Results from a second-year medical school dermatology cohort study. Int J Dermatol, 54:807-816.

Kirby A, McElroy B, 2003. The effect of attendance on grade for first year economics students in University College Cork. Econ Soc Rev, 34: 311-326.

Romer D, 1993. Do students go to class? Should they? J Econ Perspect, 7(3): 167-174.

Stanca $L, 2006$. The effects of attendance on academic performance: Panel data evidence for introductory microeconomics. J Econ Education, 37(3): 251-266.

Citation: Fadelelmoula T, 2018. The impact of class attendance on student performance. Int ResJ Med Med Sci, 6(2): 47-49. 